\title{
A novel curcumin analogue is a potent chemotherapy candidate for human hepatocellular carcinoma
}

\author{
JI-AN ZHAO ${ }^{1}$, MEI-XIANG SANG ${ }^{2}$, CUI-ZHI GENG ${ }^{2}$, SHI-JIE WANG ${ }^{2}$ and BAO-EN SHAN ${ }^{2}$ \\ ${ }^{1}$ Department of Hepatobiliary Surgery, The First Affiliated Hospital, Hebei Medical University, Shijiazhuang, Hebei 050013; \\ ${ }^{2}$ Tumor Research Institute, The Fourth Affiliated Hospital, Hebei Medical University, Shijiazhuang, Hebei 050011, P.R. China
}

Received May 16, 2015; Accepted August 10, 2016

DOI: $10.3892 / 01.2016 .5126$

\begin{abstract}
Curcumin (CUR) has been demonstrated to protect against carcinogenesis and to prevent tumor development in cancer; however, the clinical application of CUR is limited by its instability and poor metabolic properties. The present study offers an strategy for a novel CUR analogue, (1E,4E)-1,5-bis(2-bromophenyl)penta-1,4-dien-3-one (GL63), to be used as a potential therapeutic agent for hepatocellular carcinoma (HCC) in vitro and in vivo. The current study demonstrated that GL63 exhibited more potent inhibition of proliferation of HCC cells than CUR. GL63 induced G0/G1 phase cell cycle arrest and apoptosis in SK-HEP-1 cells in a dose-dependent manner, and was more potent than CUR, according to the flow cytometry data. The present study demonstrated for the first time that the inhibition of the Janus kinase 2 (JAK2)/signal transducer and activator of transcription 3 (STAT3) signaling pathway by GL63 resulted in a protective effect against HCC cell growth. GL63 was more effective than CUR in regulating STAT3 downstream targets, which contributed to the suppression of cell proliferation and the induction of cell apoptosis. In addition, the effects of GL63 were tested in a model of N-nitrosodiethylamine (DEN)-induced HCC in Wistar rats. Although macroscopic and microscopic features suggested that both GL63 and CUR were effective in inhibiting DEN-induced hepatocarcinogenesis, GL63 exerted a stronger effect than CUR. Immunohistochemical analysis for proliferating cell nuclear antigen demonstrated significant differences among the DEN-bearing non-treated, DEN-bearing GL63-treated and DEN-bearing, CUR-treated groups $(\mathrm{P}=0.039)$. It was concluded that GL63 was a potent agent able to suppress the proliferation of HCC cells by inhibition of the JAK2/STAT3 signaling pathway, with more favorable pharmacological activity than CUR, and may be a
\end{abstract}

Correspondence to: Professor Bao-En Shan, Tumor Research Institute, The Fourth Affiliated Hospital, Hebei Medical University, 12 Health Road, Shijiazhuang, Hebei 050011, P.R. China

E-mail: baoenshan2015@hotmail.com

Key words: hepatocellular carcinoma, curcumin, analogue, diethylnitrosamine, signaling pathway more potent compound for the prevention of DEN-induced hepatocarcinogenesis in rats than CUR.

\section{Introduction}

Hepatocarcinoma is one of the major malignant tumors in humans, with $\sim 600,000$ newly diagnosed cases, and leading to $>250,000$ mortalities annually $(1,2)$. Surgical resection, in the form of partial hepatectomy or total hepatectomy, followed by liver transplantation, may provide an occasional incidence of cure (3). However, this can be performed only in selected patients whose tumors are small and located away from major vessels and have not metastasized to extrahepatic organs (4). No chemotherapy agent has better benefit than surgery in controlled clinical trials due to different reasons, including drug resistance and toxicity to normal cells (5).

The development of innovative novel therapeutics for the management of hepatocarcinoma is particularly urgent, and this development is the long-term objective of the current study. Curcumin (CUR) has been reported to interrupt the cell cycle, exert cytotoxic effects, and participate in antiproliferation and induction of apoptosis in numerous hepatocarcinoma cell lines in vitro (6). A considerable number of reports have also described the anticancer effects of CUR on hepatocellular carcinoma (HCC) in vivo (7). Although CUR is remarkably non toxic and has promising anticancer activities, preclinical and clinical studies indicate that its poor bioavailability and pharmacokinetic profile due to its instability under physiological conditions have limited its application in anticancer therapies (8-10). Thus, the development of synthetic structural analogues of CUR is one approach for overcoming the poor bioavailability of CUR while retaining or further enhancing its drug-like effects $(11,12)$. The present authors have designed and synthesized a series of mono-carbonyl analogues of CUR by deleting the reactive $\beta$-diketone moiety (13-15). Although previous studies suggest that the presence of the $\beta$-diketone moiety may be necessary for the biological activities of CUR, a number of studies from several independent groups demonstrated that certain CUR analogues containing a 5 -carbon enone spacer without $\beta$-diketone either retained or increased the growth-suppressive activities of CUR against several cancer cells $(16,17)$. Those studies indicate that certain mono-carbonyl analogues not only have enhanced stability and antitumor activities in vitro, but also 
have better pharmacokinetic profiles in vivo than CUR (18). One such compound, (1E,4E)-1,5-bis(2-bromophenyl) penta-1,4-dien-3-one (GL63) was synthesized as part of a series of novel CUR analogues (19).

Upon oral administration at a dose of $500 \mathrm{mg} / \mathrm{kg}$ GL63 and CUR to rats, the concentration of each compound in plasma was measured by high performance liquid chromatography (20). GL63 was observed to possess a plasma concentration $~ 44$-fold higher than that of CUR (area under the curve) and a peak blood concentration $\sim 45$-fold higher than that of CUR (20). Furthermore, there was an apparent decrease in clearance with GL63 (38.98 1/kg/h) compared with CUR (835.20 1/kg/h) (20). In summary, these pharmacokinetics data indicate that the deletion of the $\beta$-diketone moiety significantly decreases the degree and speed of metabolism of curcuminoids, and that GL63 possesses a much better pharmacokinetic profile than CUR (20). Previous studies demonstrated that the cytotoxic effect of GL63 against HepG2 human hepatocellular carcinoma and CNE2 nasopharyngeal carcinoma cells was due to the induction of cell cycle arrest and subsequent apoptosis by the endoplasmic reticulum stress pathway $(21,22)$. Xiao et al noticed that treatment of H460 human lung epithelial cancer cells with GL63 facilitated the degradation of cyclooxygenase-2 messenger (m) RNA, as evidenced by mRNA degradation assay (19). Xiao et al also observed that neither GL63 nor CUR induced apoptosis in normal liver cells, which indicated that GL63 had no significant toxicity, similar to CUR (21). These results suggested that the novel CUR-related compound GL63 is a potent antitumor agent. To date, although GL63 has been used for various different medical purposes in vitro $(21,22)$, the underlying cellular and molecular mechanisms by which GL63 suppresses hepatocarcinoma cell growth are unknown. Whether GL63 has potential as a novel therapeutic agent for hepatocarcinoma to the same extent than CUR remains to be investigated. In the present study, the inhibitory efficacy of GL63 was evaluated on hepatocarcinoma in vitro and in vivo, and it was assessed whether GL63 was more potent than CUR in inhibiting the growth of liver cancer cell lines (SK-HEP-1) and of hepatocarcinoma induced by $\mathrm{N}$-nitrosodiethylamin (DEN) in a Wistar rat model.

\section{Materials and methods}

Cell lines and reagents. GL63 was synthesized as reported by Liang et al (20). The SK-HEP-1 cell line was purchased from the Cell Bank of the Type Culture Collection of the Chinese Academy of Sciences (Shanghai, China). Cells were cultured in RPMI-1640 medium (Sigma-Aldrich; Merck Millipore, Darmstadt, Germany) with $10 \%$ fetal bovine serum (FBS; Sigma-Aldrich; Merck Millipore) and antibiotics (100 U/ml penicillin and $100 \mu \mathrm{g} / \mathrm{ml}$ streptomycin) in cell culture incubators set at $37^{\circ} \mathrm{C}$ and aired with $5 \% \mathrm{CO}_{2}$.

3-(4,5-dimethylthiazol-2-yl)-2,5-diphenyltetrazolium bromide (MTT) cell viability assay. The MTT assay was used to evaluate cell viability. Briefly, cells were seeded onto 96-well plates, and allowed to adhere and grow in $10 \%$ FBS-containing RPMI-1640 medium for 24 h. GL63 (Hebei University of Science and Technology, Shijiazhuang, China) and CUR (Hebei University of Science and Technology) were dissolved in dimethyl sulfoxide (DMSO). The cells were then treated with various concentrations of GL63 and CUR $(0,10$, 20 and $40 \mu \mathrm{M})$ for $24 \mathrm{~h}$. MTT $(20 \mu \mathrm{l}$ at $5 \mathrm{mg} / \mathrm{ml})$ was added to each well, and incubation was conducted for $3.5 \mathrm{~h}$. MTT was aspirated, and $100 \mu \mathrm{l}$ DMSO was added to each well. Next, the absorbance at $570 \mathrm{~nm}$ was read in a plate reader. The half-maximal inhibitory concentration $\left(\mathrm{IC}_{50}\right)$ was used as the concentration of drug required to obtain $50 \%$ of maximal inhibition in cell viability. Each treatment was performed in triplicate. The mean of three values was determined, and the results were expressed as a percentage of the control. Cell viability was expressed as the percentage of the absorbance in the treated wells relative to that of the untreated (control) wells. Three independent experiments were performed.

Cell cycle analysis. SK-HEP-1 cells were seeded in 6-well plates at a concentration of $5 \times 10^{5}$ cells/well. Following treatment with various concentrations of GL63 and CUR (0, 10, 20 and $40 \mu \mathrm{M})$ for $24 \mathrm{~h}$, the cells were harvested and washed with phosphate-buffered saline (PBS), and then resuspended in $70 \%$ ethanol at $-20^{\circ} \mathrm{C}$ overnight. Next, the cells were washed twice with PBS and $10 \mathrm{mg} / \mathrm{ml}$ RNase A was added. Propidium iodide (PI) was added to the tubes at a final concentration of $0.05 \mathrm{mg} / \mathrm{ml}$ and incubated at $4^{\circ} \mathrm{C}$ for $30 \mathrm{~min}$ in the dark. Cell cycle analysis was conducted immediately upon staining using an EPICS Elite ESP flow cytometer (Beckman Coulter, Inc., Brea, CA, USA) and WinMDI 2.9 software (Beckman Coulter, Inc.).

Flow cytometric analysis. SK-HEP-1 cells were seeded in 6 -well plates at a density of $5 \times 10^{5}$ cells/well for $24 \mathrm{~h}$ at $37^{\circ} \mathrm{C}$, incubated with $20 \mu \mathrm{M}$ Z-DEVD-FMK (Santa Cruz Biotechnology Inc., Santa Cruz, CA, USA) or vehicle for $1 \mathrm{~h}$, followed by treatment with various concentrations of GL63 and CUR $(0,10,20$ and $40 \mu \mathrm{M})$ for $24 \mathrm{~h}$. All cells were collected and washed twice with cold PBS. Next, the cells were collected and resuspended in $100 \mu \mathrm{l}$ binding buffer containing annexin $\mathrm{V}$ and PI. The mixed solution was gently vortexed and incubated in the dark at room temperature $\left(25^{\circ} \mathrm{C}\right)$ for $15 \mathrm{~min}$. Quantification of annexin $\mathrm{V}$ and PI binding was performed with a FACScan $^{\mathrm{TM}}$ (BD Biosciences, Franklin Lakes, NJ, USA).

Western blotting. Following treatment with 0, 10, 20 and $40 \mu \mathrm{M}$ CUR and GL63 for $24 \mathrm{~h}$, the culture medium was collected, and the cells were washed with ice-cold PBS. Cells were lysed with lysis buffer (Beijing Biosynthesis Biotechnology Co. Ltd., Beijing, China) for $30 \mathrm{~min}$ at $40^{\circ} \mathrm{C}$, followed by centrifugation at $20,000 \times \mathrm{g}$ for $10 \mathrm{~min}$ at $4^{\circ} \mathrm{C}$. The supernatants were collected and the protein concentrations were determined using a BCA-100 Protein Quantitative Analysis kit (Beijing Biosynthesis Biotechnology Co. Ltd.). Proteins were then subjected to electrophoresis on $10 \%$ SDSPAGE gels and transferred to a polyvinylidene difluoride blotting membrane for $1 \mathrm{~h}$ at room temperature. Membranes were blocked with $5 \%$ skim milk at room temperature for $1 \mathrm{~h}$, followed by incubation with polyclonal rabbit phosphorylated (p)-Janus kinase 2 (JAK2; cat. no. sc-16566; 1:1,000), JAK2 (cat. no. sc-278; 1:1,000), p-signal transducer and activator of transcription 3 (STAT3; cat. no. sc-135649; 1:1,000), STAT3 (cat. no. sc-7179; 1:1,000), cytochrome $c$ (Cyt-c; cat. no. sc-33174; 1:1,000), caspase-9 (cat. no. sc-7885; 1:1,000), 
caspase-3 (cat. no. sc-98785; 1:1,000), poly(ADP-ribose) polymerase (PARP; cat. no. sc-133888; 1:1,000), B-cell lymphoma (Bcl)-2 (cat. no. sc-783; 1:1,000), Bcl- extra large (xL) (cat. no. sc-7195; 1:1,000) and Bcl-2 associated X protein (Bax; cat. no. sc-493; 1:1,000) rabbit polyclonal antibody (Santa Cruz Biotechnology Inc.) primary antibodies at $4^{\circ} \mathrm{C}$ overnight. Following three washes with TBST, the membranes were incubated with horseradish peroxidase-conjugated polyclonal goat anti-rabbit IgG secondary antibody (cat. no. sc-2004; 1:10,000; Santa Cruz Biotechnology Inc.) for $1 \mathrm{~h}$ at room temperature. Chemiluminescence detection was performed using an ECL Western Blotting Detection kit (GE Healthcare Life Sciences, Chalfont, UK). The quantities of the proteins were analyzed using ImageJ 1.48 analysis software and normalized to their respective control.

Tumorigenicity assays in Wistar rats. A total of 105 healthy 4-week-old male Wistar rats (100-110 g) were provided by the Animal Center of Beijing Medical University (Beijing, China). All animals received humane care, and protocols were approved by the Hebei Medical University Animal Ethics Committee (Shijiazhuang, China). The animals were housed in a polypropylene cage at temperature of $22 \pm 2^{\circ} \mathrm{C}$ and $50-60 \%$ relative humidity, with a $12 \mathrm{~h}$ light/dark cycle for 1 week prior to and during the experiment. Rats were allowed to access standard pelleted rat chow and water. Group 1 (control non-treated group; $\mathrm{n}=10$ ) was considered as the normal control group. GL63 in group 2 (control GL63-treated group; $n=10$ ) was administered intraperitoneally $(80 \mathrm{mg} / \mathrm{kg})$ twice a week for 12 weeks. CUR in group 3 (control CUR-treated group; $\mathrm{n}=10)$ was administered intraperitoneally $(80 \mathrm{mg} / \mathrm{kg})$ twice a week for 12 weeks. The rats in group 4 (DEN-bearing non-treated group; $\mathrm{n}=25$ ) were administered an intraperitoneal injection of DEN $(50 \mathrm{mg} / \mathrm{kg}$ ) twice a week for 12 weeks. The rats in group 5 (DEN-bearing GL63-treated group; $n=25$ ) were administered both DEN as in group 4 and GL63 as in group 2. The rats in group 6 (DEN-bearing, CUR-treated group; $n=25$ ) were administered both DEN as in group 4 and CUR as in group 3. Body weight was recorded at the end of every week for 24 weeks. The experiment was terminated at the end of 24 weeks, and all the surviving rats were anaesthetized and sacrificed at the end of the experiment, following animal ethics guidelines (23).

Cytomorphological evaluation and immunohistochemistry. Autopsy specimens were obtained from the liver of rats in all groups. All the liver tissues were fixed routinely and embedded in paraffin to prepare $4-\mu \mathrm{m}$ sections for hematoxylin and eosin staining. The diagnosis and grade of hepatocarcinoma was established based on the morphological findings identified on the cell block sections using the World Health Organization criteria (24). The expression strength of proliferating cell nuclear antigen (PCNA; polyclonal rabbit antibody; cat. no. sc-7909; 1:100; Santa Cruz Biotechnology, Inc.) was based on the staining intensity ( 0 , negative; 1 , weak; 2 , intermediate; and 3 , strong) and the percentage of positive cells $(0$, $0 \%$ positive cells; $1, \leq 25 \%$ positive cells; $2,26-50 \%$ positive cells; and $3,>50 \%$ positive cells) identified following incubation with the PCNA antibody for $1 \mathrm{~h}$ at room temperature. The two scores were added, with a maximum score of 6 . A score of
$>2$ represented a positive immunohistochemical identification of the marker.

Statistical analysis. All statistical analysis was performed using SPSS 13.0 statistical software (SPSS, Inc., Chicago, IL, USA). All qualitative variables are expressed as frequencies and percentages. $\chi^{2}$ test and Fisher's exact test were used to determine associations between categorical variables. All quantitative data are expressed as the mean \pm standard deviation. $\mathrm{P}<0.05$ was considered to indicate a statistically significant difference.

\section{Results}

GL63 inhibits cell viability and proliferation more potently than CUR. The cytotoxicity that GL63 and CUR effected on SK-HEP-1 cells was assessed by MTT assay. When cultured with various concentrations of GL63 $(0,10,20$ and $40 \mu \mathrm{M})$, the proliferation of SK-HEP-1 cells was significantly suppressed in a dose-dependent manner, with an $\mathrm{IC}_{50}$ value of $14.8 \pm 1.4 \mu \mathrm{M}$, which indicated that GL63 was substantially more potent than CUR (Fig. 1). Therefore, the results indicated that GL63 could efficiently inhibit the growth of SK-HEP-1 cells to a better extent than CUR.

GL63 is more potent than CUR in inducing cell cycle arrest. In order to gain further information about the mechanism of the cell-growth inhibitory effect of GL63, the cell cycle distribution of SK-HEP-1 cells was assessed by flow cytometry following 24-h treatment with various concentrations of GL63 and CUR $(0,10,20$ and $40 \mu \mathrm{M})$. As indicated in Fig. 2, GL63 increased the number of SK-HEP-1 cells in the G0/G1 phase of the cell cycle, whereas CUR caused a weaker change in the cell cycle distribution. The average histogram plot of cell-cycle analysis also indicated that GL63 treatment induced a dose-dependent accumulation of SK-HEP-1 cells in G0/G1 phase. These results suggested that GL63 caused a cell-cycle arrest in $\mathrm{G} 0 / \mathrm{G} 1$ phase.

GL63 promotes cell apoptosis more potently than CUR. To further investigate the underlying mechanism of decreased cell proliferation, the apoptosis of SK-HEP-1 cells induced by GL63 was examined using annexin V/PI assay (Fig. 3A and B). The apoptosis of SK-HEP-1 cells (including early and late apoptotic cell death) increased in a dose-dependent manner following treatment with GL63 for $24 \mathrm{~h}$. Furthermore, GL63 significantly induced apoptosis compared with CUR at the same concentrations in SK-HEP-1 cells. Bcl and caspase family proteins are widely accepted to mediate the apoptotic pathway (25). Mitochondrial apoptotic pathway-related proteins (caspase-3, caspase-9, Cyt-c and PARP) were upregulated by GL63 treatment, suggesting that this apoptotic pathway was activated (Fig. 3C and D). It was observed an increased activation of caspase-3 in SK-HEP-1 cells treated with increasing concentrations of GL63, indicating that GL63-induced apoptosis was dependent upon caspase-3 activity. A similar tendency was observed for caspase-9, Cyt-c and PARP. Since caspase-9 activation involves mitochondria permeability changes and the release of Cyt-c (21), a significant increase in released Cyt-c was detected by GL63 treatment 

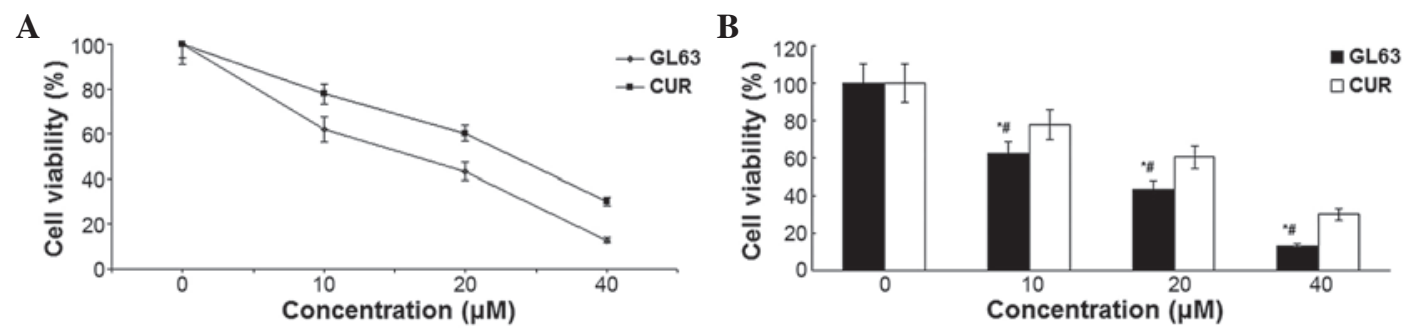

Figure 1. Analysis of cell viability. (A) Effect of GL63 and CUR on the cell viability of SK-HEP-1 cells following treatment with 0-40 $\mu$ M GL63 and CUR for $24 \mathrm{~h}$. Cell viability was determined by 3-(4,5-dimethylthiazol-2-yl)-2,5-diphenyltetrazolium bromide assay. (B) Bar diagram of cell viability analysis from three independent treatments. Data are presented as the mean \pm standard deviation. ${ }^{~} \mathrm{P}<0.05$ vs. dimethyl sulfoxide control. ${ }^{~} \mathrm{P}<0.05$ vs. CUR group at the same concentration. CUR, curcumin; GL63, (1E,4E)-1,5-bis(2-bromophenyl)penta-1,4-dien-3-one.

A
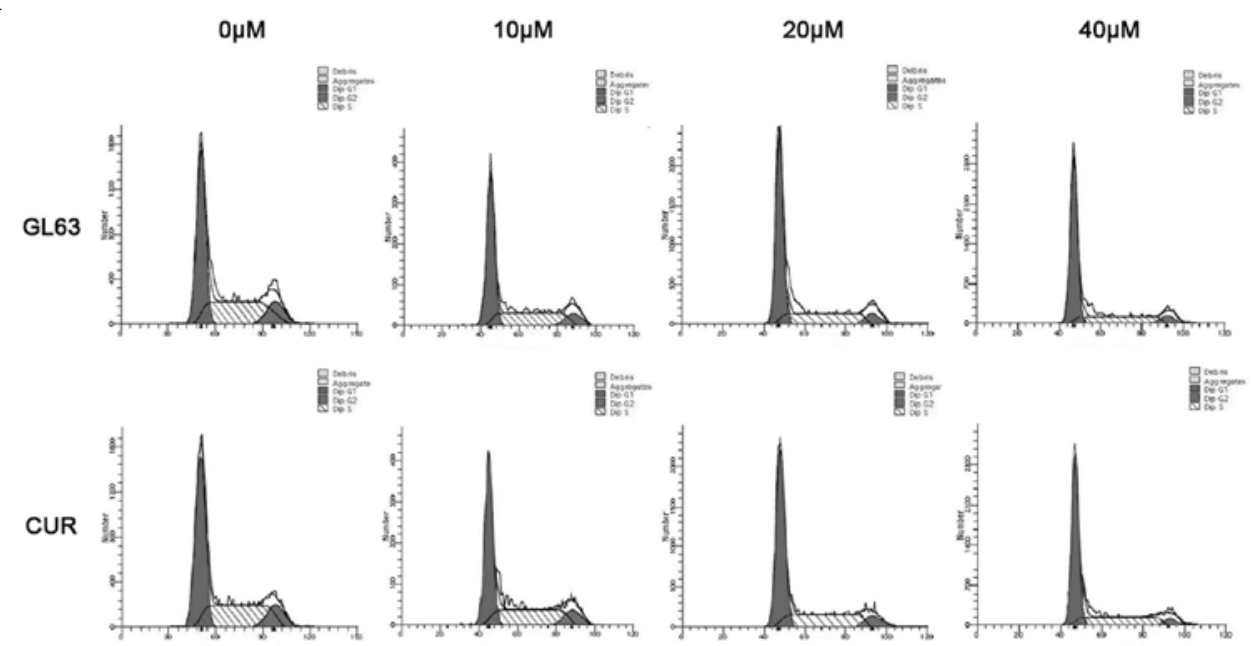

B

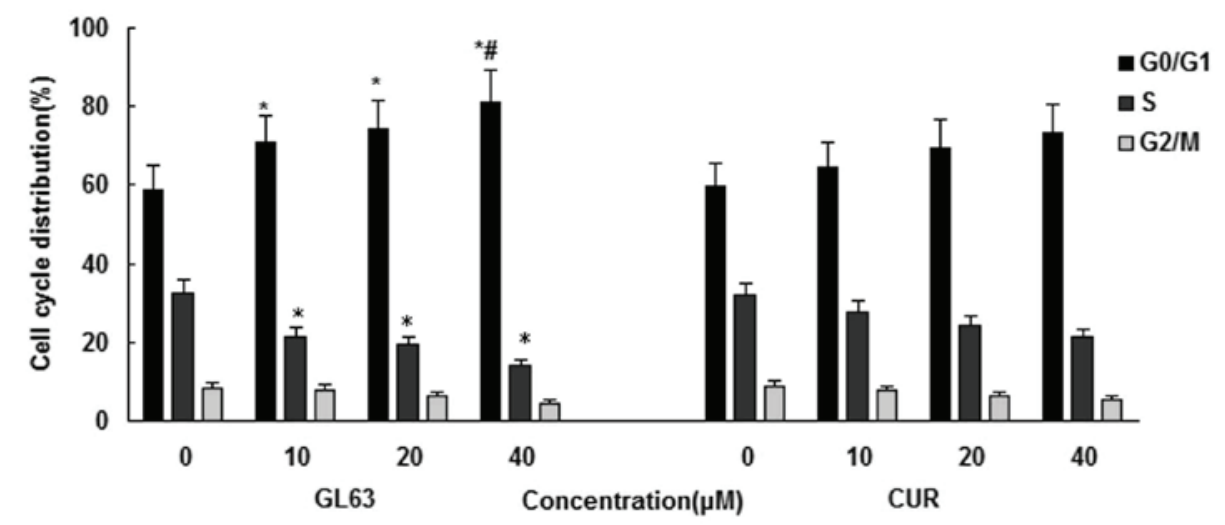

Figure 2. Effects of GL63 and CUR on cell cycle distribution in SK-HEP-1 cells. (A) SK-HEP-1 cells were treated with GL63 and CUR (0, 10, 20 and $40 \mu \mathrm{M}$ ) for $24 \mathrm{~h}$, stained with propidium iodide and analyzed with a BD FACScan ${ }^{\mathrm{TM}}$ flow cytometer. (B) Bar graph of cell cycle distribution representing the mean \pm standard deviation from three independent experiments. ${ }^{*} \mathrm{P}<0.05$ vs. dimethyl sulfoxide control. ${ }^{*} \mathrm{P}<0.05$ vs. CUR group at the same concentration. CUR, curcumin; GL63, (1E,4E)-1,5-bis(2-bromophenyl)penta-1,4-dien-3-one.

at various doses. Cells were pretreated with the caspase-3 inhibitor Z-DEVD-FMK prior to and throughout treatment with GL63, and it was observed that Z-DEVD-FMK almost completely inhibited GL63-induced apoptosis in SK-HEP-1 cells, indicating that GL63-induced apoptosis was dependent upon caspase-3 activity (Fig. 3E). Notably, CUR did not induce caspase activation markedly, compared with GL63. These in vitro results support a mitochondria-dependent caspase activation to mediate GL63-induced apoptosis. The details of the mechanisms by which GL63 affects the mitochondria to initiate apoptosis signaling pathways will require further investigation.
GL63 potently suppresses the JAK2/STAT3 signaling pathway and regulates the expression of its downstream targets in vitro. To characterize the molecular mechanism by which the JAK2/STAT3 signaling pathway alters GL63-induced apoptosis in SK-HEP-1 cells, the expression of proteins in response to GL63 was examined by immunoblotting. The results indicated that the levels of JAK2 and STAT3 were not altered, while the levels of p-JAK2 and p-STAT3 were markedly and concentration-dependently reduced following treatment with GL63 and CUR in SK-HEP-1 cells. GL63 significantly reduced the level of p-JAK2 and p-STAT3 at various concentrations, while CUR 
A
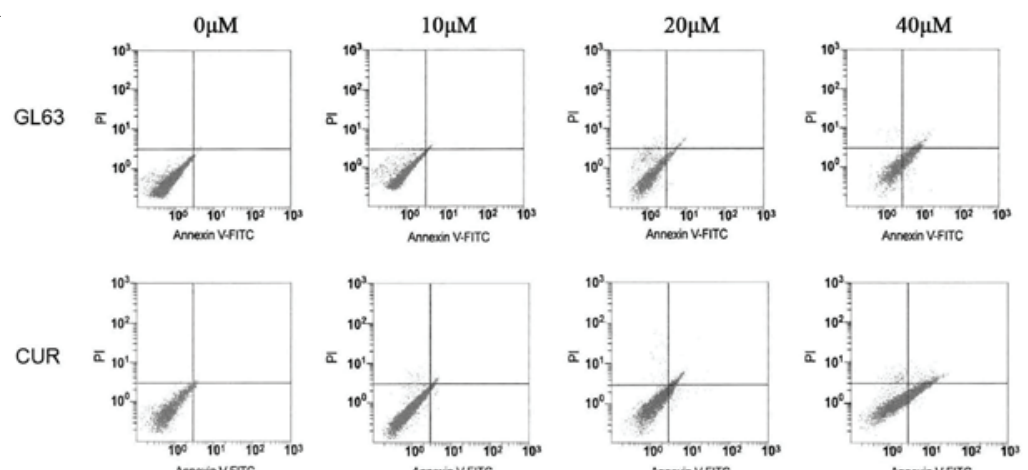

B

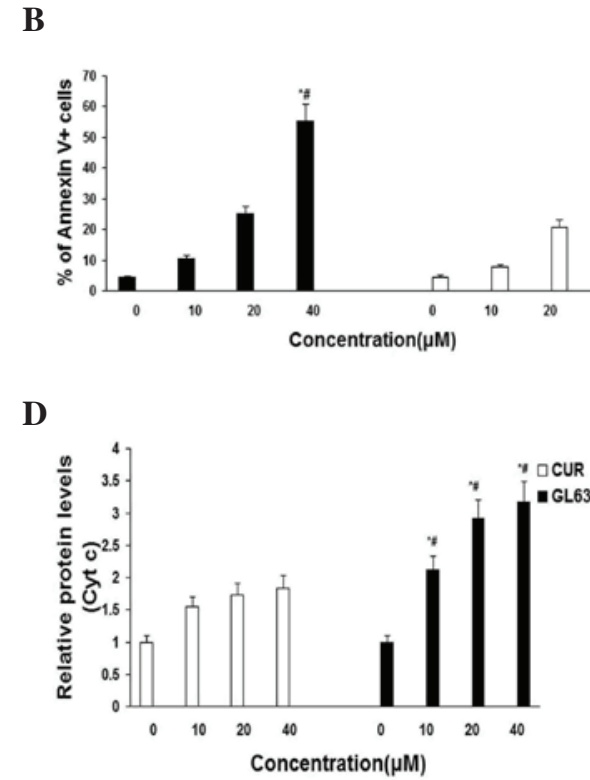

C
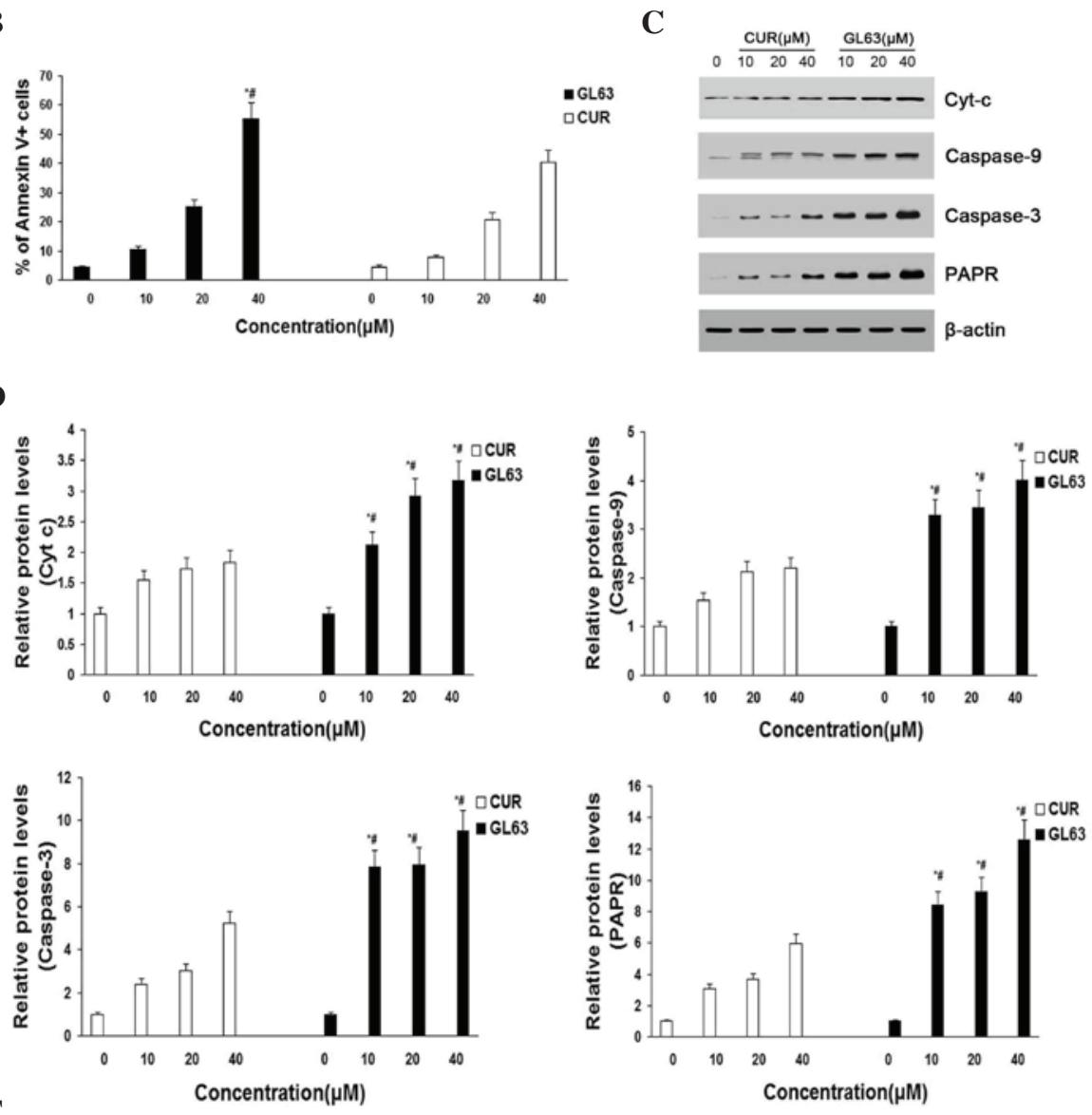

$\mathbf{E}$

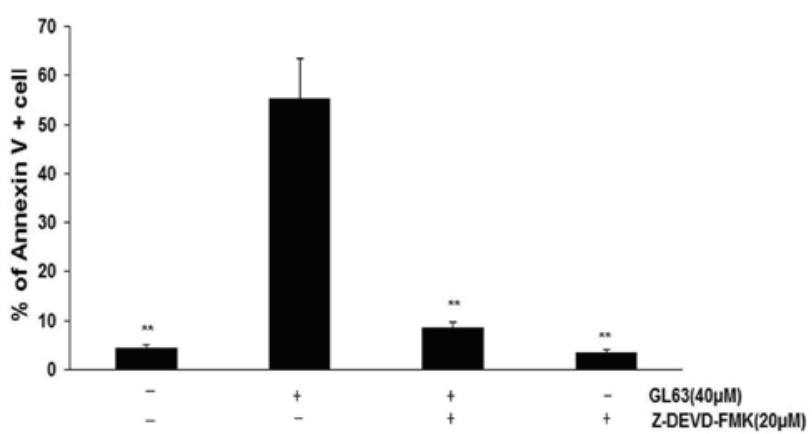

Figure 3. Apoptosis rates of SK-HEP-1 cells subjected to GL63 and CUR treatment, as detected by flow cytometry and protein expression analysis. SK-HEP-1 cells were treated with GL63 and CUR $(0,10,20$ and $40 \mu \mathrm{M})$ for $24 \mathrm{~h}$. (A) Representative diagrams of annexin V-fluorescein isothiocyanate/propidium iodide staining upon treatment with different concentrations of GL63 and CUR. (B) Bar diagram of apoptotic cell rate from three FACS analyses from three separate treatments. (C) Caspase-9, caspase-3, Cyt-c and PARP levels were determined in SK-HEP-1 cells treated with GL63 and CUR at various concentrations for 24 h. $\beta$-actin was used as a protein loading control. (D) Bar diagram represents the expression levels of caspase-9, caspase-3, Cyt-c and PARP, which displayed a concentration-dependent increase upon treatment with GL63 or CUR. (E) Z-DEVD-FMK inhibits GL63-induced apoptosis. SK-HEP-1 cells were incubated with Z-DEVD-FMK $(20 \mu \mathrm{M})$ or vehicle for $1 \mathrm{~h}$, followed by treatment with or without GL63 $(40 \mu \mathrm{M})$ for another $24 \mathrm{~h}$, and then apoptosis was evaluated by FACS $\left({ }^{* *} \mathrm{P}<0.01\right.$ vs. GL63 alone treatment). All data were expressed as the mean \pm standard deviation of $\geq 3$ separate experiments. ${ }^{*} \mathrm{P}<0.05$ vs. dimethyl sulfoxide control. ${ }^{*} \mathrm{P}<0.05$ vs. CUR group at the same concentration. CUR, curcumin; FITC, fluorescein isothiocyanate; PI, propidium iodide; Cyt-c, cytochrome $c$; PARP, poly(ADP-ribose) polymerase; FACS, fluorescence-activated cell sorting; GL63, (1E,4E)-1,5-bis(2-bromophenyl)penta-1,4-dien-3-one. 


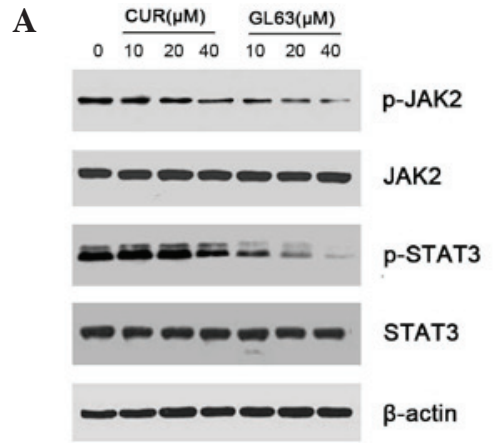

C
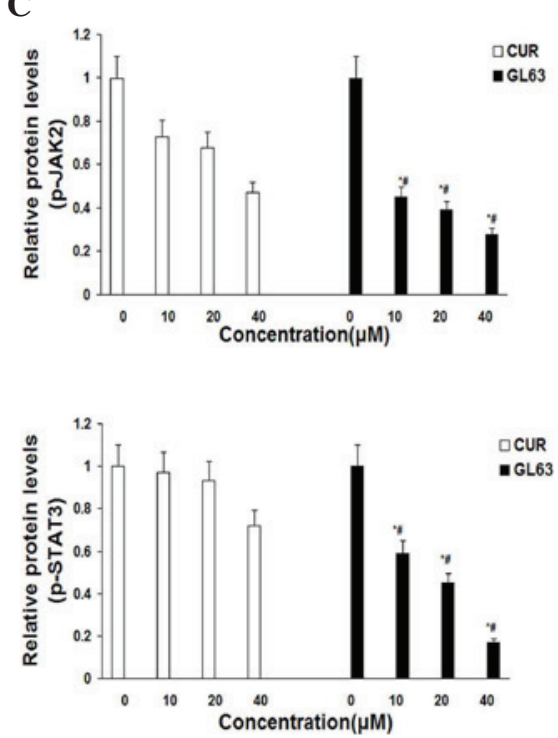

B
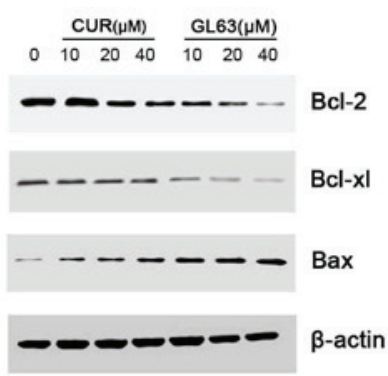

D
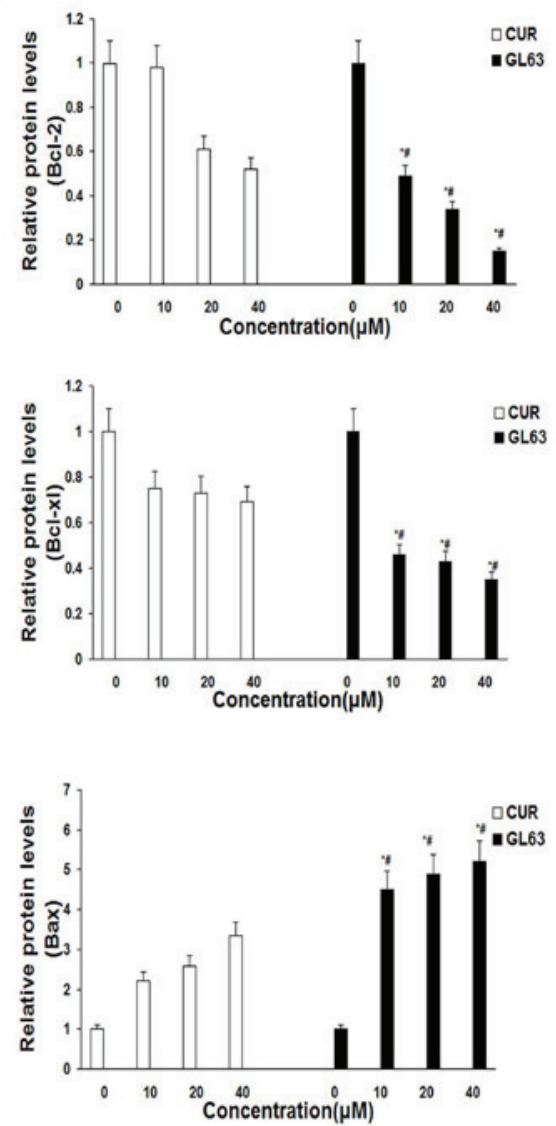

Figure 4. GL63 and CUR both reduce cell viability in human SK-HEP-1 cells by inhibiting the JAK2/STAT3 signaling pathway and its downstream gene expression. (A) SK-HEP-1 cells were treated with the indicated concentrations of GL63 and CUR for $24 \mathrm{~h}$ prior to be subjected to western blot analysis with anti-p-JAK2, anti-JAK2, anti-p-STAT3 and anti-STAT3 antibodies. (B) Bar diagram of the effects of the different concentrations of GL63 and CUR on p-JAK2 and p-STAT3 from three separate treatments for $24 \mathrm{~h}$. (C) Representative immunoblots of Bcl-2, Bcl-xl and Bax from the nuclear extracts of SK-HEP-1 cells treated with GL63 and CUR $(0,10,20$ and $40 \mu \mathrm{M})$ for $24 \mathrm{~h}$. $\beta$-actin served as a loading control. (D) Bar diagram of the effects of the different concentrations of GL63 and CUR on STAT3 downstream gene expression from three separate treatments. Data are presented as the mean \pm standard deviation. ${ }^{*} \mathrm{P}<0.05$ vs. dimethyl sulfoxide control. " $\mathrm{P}<0.05$ vs. CUR group at the same concentration. CUR, curcumin; JAK2, Janus kinase 2; STAT3, signal transducer and activator of transcription 3; p-, phosphorylated; Bcl-2, B-cell lymphoma-2; Bcl-XL, B-cell lymphoma-extra large; Bax, Bcl-2 associated X protein; GL63, (1E,4E)-1,5-bis(2-bromophenyl)penta-1,4-dien-3-one.

only slightly reduced p-JAK2 and p-STAT3 expression (Fig. 4A and C). To further investigate whether GL63 could affect STAT3 downstream genes, western blot analysis was used to examine the expression of Bcl-2, Bcl-xL and Bax. The results indicated that cells treated with GL63 exhibited a strong reduction in the protein expression levels of $\mathrm{Bcl}-2$ and $\mathrm{Bcl}-\mathrm{xL}$ and a concomitant increase in Bax expression in a concentration-dependent manner, compared with CUR (Fig. 4B and D).

Liver tumor formation. Table I presents the results of survival, tumor incidence and number of nodules per nodule-bearing liver in rats. The hepatocarcinogenic rats were infiltrated with a large number of nodules, thus making the precise assessment of tumor mass impossible. The literature reports that, in previous studies, nodules measuring $>6 \mathrm{~mm}$ in diameter at week 24 were always hepatocarcinoma (26); thus, in the present study, those nodules were quantified according to this standard when detected at the surface of the liver. As indicated in Table I, no tumors were observed in the untreated control group (group 1) or in the GL63 or CUR control groups (groups 2 and 3). A significant reduction in tumor incidence was observed in the GL63 and CUR-treated groups (group 5 and 6) compared with 
Table I. Effect of GL63 and CUR on the survival and development of nodules on DEN-induced hepatocarcinogenesis in rats.

\begin{tabular}{lcccc}
\hline Group & Treatment & Survival, $\%$ & $\begin{array}{c}\text { Average count of nodules/ } \\
\text { Tumodules incidence, } \%\end{array}$ & - \\
\hline 1 & Control & $100.0(10 / 10)$ & - & - \\
2 & GL63 alone & $100.0(10 / 10)$ & - & - \\
3 & CUR alone & $100.0(10 / 10)$ & $100.0(25 / 25)^{\mathrm{a}}$ & $17.53 \pm 1.29^{\mathrm{a}}$ \\
4 & DEN alone & $52.0(13 / 25)^{\mathrm{a}}$ & $20.0(5 / 25)^{\mathrm{c}}$ & $10.75 \pm 1.72^{\mathrm{c}}$ \\
5 & DEN + GL63 & $92.0(23 / 25)^{\mathrm{c}}$ & $36.0(9 / 25)^{\mathrm{c}}$ & $13.14 \pm 1.64^{\mathrm{c}}$ \\
6 & DEN + CUR & $80.0(20 / 25)^{\mathrm{b}}$ & - & - \\
\hline
\end{tabular}

Results are expressed as the mean \pm standard deviation. ${ }^{\mathrm{a}} \mathrm{P}<0.01$ vs. control group. ${ }^{\mathrm{b}} \mathrm{P}<0.05,{ }^{\mathrm{c}} \mathrm{P}<0.01$ vs. DEN alone group. DEN, N-nitrosodiethylamine; CUR, curcumin; GL63, (1E,4E)-1,5-bis(2-bromophenyl)penta-1,4-dien-3-one.

Table II. Effect of GL63 and CUR on body, liver and relative liver weights on DEN-induced hepatocarcinogenesis in rats.

\begin{tabular}{lccccc}
\hline Group & Treatment & $\begin{array}{c}\text { Gain in body } \\
\text { weight, }\end{array}$ & $\begin{array}{c}\text { Final body } \\
\text { weight, }\end{array}$ & $\begin{array}{c}\text { Liver } \\
\text { weight, g }\end{array}$ & $\begin{array}{c}\text { Relative liver } \\
\text { weight, g }\end{array}$ \\
\hline 1 & Control & $267.1 \pm 4.7$ & $371.9 \pm 5.5$ & $11.38 \pm 0.12$ & $3.06 \pm 0.04$ \\
2 & GL63 alone & $265.0 \pm 8.7$ & $371.2 \pm 9.5$ & $11.47 \pm 0.12$ & $3.10 \pm 0.08$ \\
3 & CUR alone & $263.9 \pm 4.6$ & $368.9 \pm 4.8$ & $11.48 \pm 0.11$ & $3.11 \pm 0.06$ \\
4 & DEN alone & $196.2 \pm 10.8^{\mathrm{a}}$ & $302.0 \pm 11.1^{\mathrm{a}}$ & $14.23 \pm 0.27^{\mathrm{a}}$ & $4.73 \pm 0.16^{\mathrm{a}}$ \\
5 & DEN + GL63 & $245.5 \pm 9.7^{\mathrm{c}}$ & $350.2 \pm 9.7^{\mathrm{c}}$ & $12.01 \pm 0.20^{\mathrm{b}}$ & $3.44 \pm 0.10^{\mathrm{c}}$ \\
6 & DEN + CUR & $243.4 \pm 8.1^{\mathrm{c}}$ & $347.5 \pm 8.2^{\mathrm{c}}$ & $11.95 \pm 0.30^{\mathrm{b}}$ & $3.44 \pm 0.09^{\mathrm{c}}$ \\
\hline
\end{tabular}

Results are expressed as the mean \pm standard deviation. ${ }^{\mathrm{a}} \mathrm{P}<0.01$ vs. to control group. ${ }^{\mathrm{b}} \mathrm{P}<0.05,{ }^{\mathrm{c}} \mathrm{P}<0.01$ vs. DEN alone group. DEN, N-nitrosodiethylamine; CUR, curcumin; GL63, (1E,4E)-1,5-bis(2-bromophenyl)penta-1,4-dien-3-one.

the DEN-bearing non-treated group (group 4). Groups 5 and 6 exhibited a significant decrease in the number of nodules as compared with group 4. Furthermore, GL63 appeared to be a more potent compound than CUR, with regard to decreasing tumor incidence and nodules numbers in rats. Table II presents data regarding body weight, absolute liver weight and relative liver weight of the rats from each control and experimental group. The body weights were significantly decreased in the DEN-bearing non-treated group compared with the control groups $(\mathrm{P}<0.001)$. GL63 and CUR treatment of rats with DEN significantly improved their body weight $(\mathrm{P}<0.001)$, compared with rats in group 4. Group 4 exhibited an increased liver/body weight ratio compared with group 1 . There was an appreciable decrease in the absolute and relative liver weight in groups 5 and 6 compared with rats administered DEN alone, particularly in group 5.

Histopathological observations. The histology of the liver tissue was examined under a light microscope and represented in (Fig. 5). The livers from the control non-treated group (group 1) exhibited a normal architecture and cytoplasm of hepatic cells, displaying granulated cytoplasm, a central vein, small uniform nuclei and nucleoli. Although liver tissues from rats treated with GL63 only (group 2) displayed no significant differences compared with those of the rats in the control non-treated group $(\mathrm{P}=0.267)$, they exhibited minor sinusoidal congestions. Compared with group 2, the liver tissues from rats treated with CUR only (group 3) also had a normal lobular organization, represented by a central vein, hepatic cords and sinusoids, but displayed moderate-to-severe sinusoidal and venous congestions. DEN treatment alone (group 4) resulted in the loss of the normal architecture, with the tissues displaying instead a granular cytoplasm with large hyperchromatic nuclei. Although the DEN-bearing GL63-treated group (group 5) lost the normal organization of hepatic lobules, it exhibited cancerous foci with patchy necrosis compared with group 4 . The tissues of rats in the DEN-bearing CUR-treated group (group 6) exhibited disorganized cells bordering wide sinusoids, but displayed moderately malignant features such as focal necrosis and a low mitotic count.

Immunohistochemical examinations. PCNA was expressed in the nuclei of hepatic cells. The number of PCNA-positive tumor cells was significantly lower in the DEN-bearing treated with GL63 or CUR group than in the DEN-bearing non-treated group, particularly in group 5 (all $\mathrm{P}<0.05$ ). Photomicrographs of PCNA immunohistochemical sections of various groups are represented in Fig. 6.

\section{Discussion}

The liver is the key organ of the metabolic, secretory and excretory functions in the body, and its disorders are numerous 

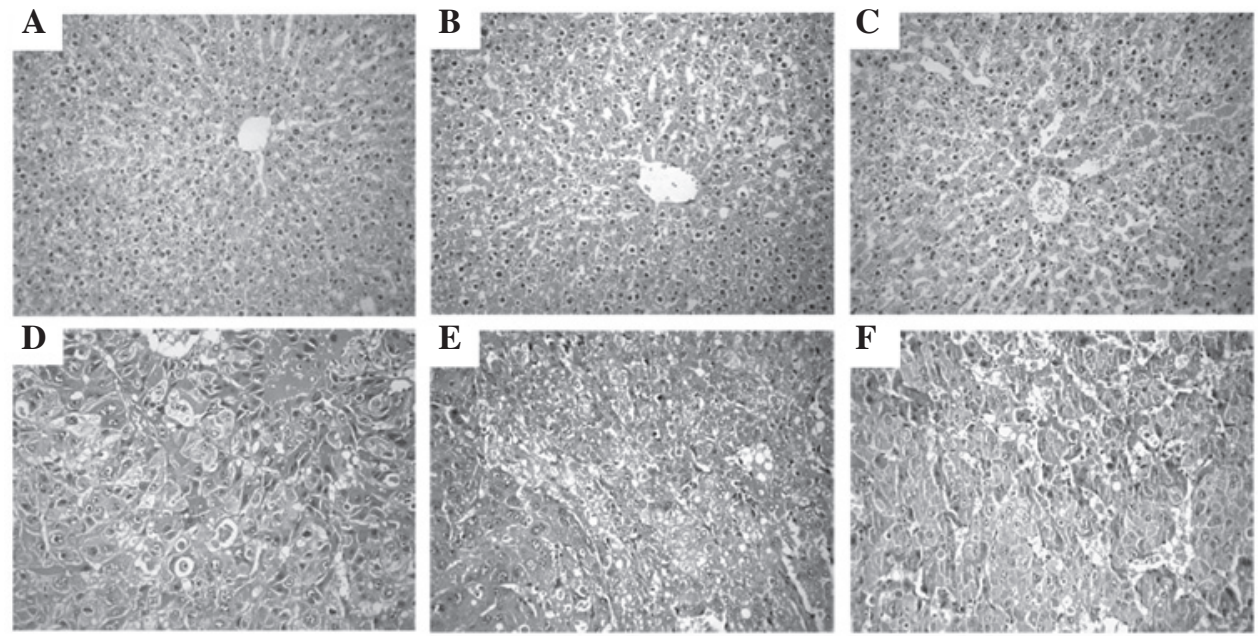

Figure 5. Observation of histopathology in liver. (A) Hepatic tissues from rats in the control non-treated group revealed a normal architecture. (B) Hepatic tissues from rats treated with GL63 only displayed mild sinusoidal and venous congestion. (C) Hepatic tissues from rats treated with CUR displayed more venous and sinusoidal congestion than those of panel B. (D) Cancerous livers from rats treated with DEN only exhibited loss of architecture with cancerous foci. (E) Liver tissues from rats in the DEN-bearing GL63-treated group exhibited a normal architecture of hepatocytes, with cancerous foci and patchy necrosis. (F) Liver tissues from rats in the DEN-bearing CUR-treated group exhibited cancerous foci with focal necrosis. Stain, hematoxylin and eosin. Magnification, x400. DEN, N-nitrosodiethylamine; CUR, curcumin; GL63, (1E,4E)-1,5-bis(2-bromophenyl)penta-1,4-dien-3-one.
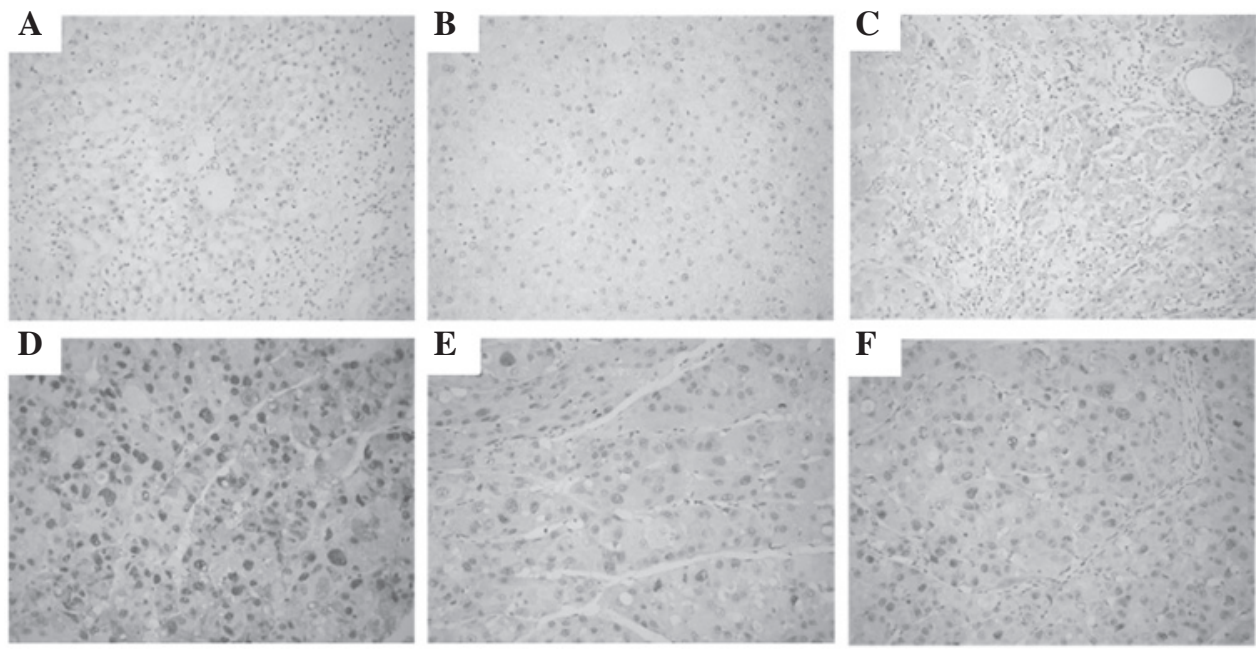

Figure 6. Immunohistochemical staining of PCNA in liver. (A) Liver from normal group displaying no PCNA staining pattern. (B) Hepatic tissues from rats treated with GL63 only exhibited very limited PCNA staining. (C) Hepatic tissues from rats treated with CUR only exhibited limited PCNA staining, similar to those of panel B. (D) Liver from rats in the DEN-positive control group displaying a number of colonies with strong PCNA staining. (E) Hepatic tissues from rats in the DEN-bearing GL63-treated group displaying moderate PCNA immunostaining. (F) The DEN-bearing CUR-treated group exhibited more PCNA staining than the DEN-bearing GL63-treated group. Magnification, x400. PCNA, proliferating cell nuclear antigen; DEN, N-nitrosodiethylamine; CUR, curcumin; GL63, (1E,4E)-1,5-bis(2-bromophenyl)penta-1,4-dien-3-one.

and varied (27). Several environmental carcinogens have been reported to elicit hepatic tumorigenesis (28).

Animal models such as Wistar rats can be used to simulate carcinogenesis and development of human hepatocarcinoma, and to study its molecular mechanism and intervention (29). DEN is a powerful carcinogen known to induce carcinoma in all animal species including humans, and is considered as an initiating agent in certain two-stage (initiation and promotion) protocols for hepatocarcinogenic studies (30). DEN-induced lesions and tumors in rodents exhibit marked biochemical, histological and molecular similarity to the progression of HCC in humans (31). DEN is an established powerful hepatocarcinogen in rats, possibly by altering the DNA structure, forming alkyl DNA adducts, and inducing chromosomal aberrations and micronuclei in the liver $(32,33)$.

Granado-Serrano et al reported a decrease in food intake, feed efficiency ratio and body weight gain, as well as a significant increase in relative liver weight, in the DEN group compared with the normal control group (34). The present results also confirmed this tendency. The reduction in food intake, and consequently, the reduction in body weight gain observed in DEN-treated animals may be due to losses of skeletal muscle and adipose tissue, with relative sparing of visceral proteins, as mentioned by Sreepriya and Bali (35), and it could be considered as an indirect indication of the declining hepatic function following exposure to DEN. Sivaramakrishnan et al reported a marked loss in body weight and 
an increase in liver weight induced by DEN in animals treated with DEN compared with the control group. In addition, the administration of DEN to animals also caused a significantly increase in liver weight due to the formation of nodules and tumors in the liver following carcinogen exposure (36). In accordance to the above report, the present study also observed a decrease in body weight and an increase in liver weight in animals treated with DEN. PCNA, as an index of the state of cell proliferation and indication of the malignant degree, was significantly enhanced in the nucleus of hepatocarcinoma cells, which has been confirmed in numerous studies (37). Therefore, enhanced expression of PCNA indicates abnormal proliferation of liver tissue. The present results demonstrated that GL63 treatment led to a decreased expression of PCNA in Wistar rats, which supported the preventive effects of GL63 against DEN-induced hepatocarcinogenesis in rats suggested by the present histopathological and immunohistochemical findings.

Due to its poor solubility and stability in water, the therapeutic benefit of CUR is limited (10). A series of mono-carbonyl analogues of CUR with higher potencies and improved water solubility, formulation and delivery system have been developed, since these properties are considered to be responsible for their stability in vitro and the pharmacokinetic advantages in vivo (20). In the present study, annexin V/PI staining demonstrated that, compared with CUR, GL63 increased the efficacy of induction of apoptosis in SK-HEP-1 cells. The results of flow cytometry also revealed that treatment with GL63 resulted in G0/G1 arrest of cancer cells, which may account for the inhibition of proliferation and cell cycle arrest exhibited by treated cells. Furthermore, the apoptotic rate induced by GL63 was higher than that induced by CUR. Based on these findings, a series of experiments were performed to further determine the potential apoptotic signaling pathways.

It is known that the dysregulation of the JAK/STAT signaling pathway may cause immunodeficiencies and cancers $(38,39)$. Activated JAK2/STAT3 signaling pathway can modulate the expression of target genes that are involved in various physiological functions, including anti-apoptotic proteins (Bcl-xl and $\mathrm{Bcl}-2$ ), pro-apoptotic proteins (Bax and $\mathrm{BH} 3$ interacting-domain death agonist) and mitochondrial apoptosis pathway-related proteins (caspase-3, caspase-9, Cyt-c and PARP) (40). Importantly, the activated JAK2/STAT3 signaling pathway has been extensively validated as a novel molecular target for the treatment of human tumors (41). The present study further explored the role of the JAK2/STAT3 signaling pathway in the anti-hepatocarcinoma effect of GL63 for the first time, and evaluated that GL63 could efficiently inhibit the phosphorylation of JAK2 and STAT3, thus affecting cell viability and inducing apoptosis. GL63 can inhibit the JAK2/STAT3 signaling pathway with lower doses than those required for CUR, thus being a more efficient form of treatment for hepatocarcinoma than CUR. The present authors suggest that GL63 may have inhibitory effects on the proliferation of SK-HEP-1 cells, which may be mediated through the suppression of the JAK2/STAT3 signaling pathway.

Previous studies have demonstrated that the regulation of the JAK2/STAT3 signaling pathway by diverse drugs can induce apoptosis through the intrinsic mitochondrial pathway (42). The intrinsic pathway is initiated at the level of the mitochondria under the regulation of the Bcl-2 family of proteins (43). Mitochondrial integrity and apoptosis are regulated mainly by the Bcl-2 family of cell-death regulatory molecules, which include the pro-apoptotic Bax and the anti-apoptotic Bcl-2 (44). Mitochondria mediate apoptotic signaling via the activation of the cell-death initiator pro-caspase-9 (45). Activated caspase-9 in turn cleaves executioner caspase-3 (46). The activated caspase-3 then cleaves PARP, a nuclear protein associated with the process of programmed cell death (47). The present data support the scenario that GL63 treatment induced apoptosis of SK-HEP-1 cells possibly through the caspase family proteins, leading to Cyt-c release and the activation of caspase-9, caspase- 3 and PARP. It was observed that the antitumor activity of GL63 was also associated with the induction of apoptosis in HCC cells, as indicated by increased caspase-9, caspase- 3 and PARP cleavage in vitro. In the present study, it was also revealed that the activation of caspase was involved in GL63-induced apoptosis, and a general caspase inhibitor markedly blocked GL63-induced cell death. These results suggested that GL63 induced apoptosis of SK-HEP-1 cells via a mitochondria-mediated intrinsic apoptosis pathway. Activation of the intrinsic pathway with GL63 was demonstrated by the activation of caspase- 9 and caspase- 3 , along with the altered expression of Bcl-2 family proteins. In the current study, the significantly increased levels of Bcl-2 and Bcl-xL, and the activation of caspases- 9 and -3 , suggested that the intrinsic pathway is important in GL63-induced apoptosis in SK-HEP-1 cells. Compared with CUR, GL63 increased the efficacy of induction of apoptosis of SK-HEP-1 cells. GL63 treatment resulted in a reduction in JAK2 and STAT3 phosphorylation, activated caspase-9, caspase-3, Cyt-c and PARP cleavage, and caused apoptotic death of cells remarkably. This finding verifies previous studies reporting that inhibiting the JAK2/STAT3 signaling pathway is associated with the induction of apoptosis by the intrinsic mitochondrial pathway in hepatocarcinoma cells (48). It was also concluded that GL63 treatment inhibits hepatocarcinoma cell growth via downregulation of the JAK2/STAT3 signaling pathway.

The activity of GL63 was also evaluated in the present study using male Wistar rats, which is an animal model for studies of human hepatocarcinoma (49). For these in vivo studies, rats were divided into six different groups according to the requirements of the experimental design, and the animals were injected DEN into the peritoneum to induce hepatocarcinoma. A series of indexes of hepatocarcinoma were recorded for each group to judge the protective role of GL63 and CUR against hepatocarcinoma in rats. Although the results of the present study provide support for the chemopreventive effects of GL63 and CUR, GL63 could be a more potent compound than CUR for the prevention of DEN-induced hepatocarcinogenesis in rats.

In conclusion, the present results demonstrated that, compared with CUR, GL63 was more effective in inhibiting the JAK2/STAT3 signaling pathway and regulating the activation of the intrinsic mitochondrial pathway with a more favorable pharmacological activity than CUR, which contributed to the suppression of cell proliferation and the 
induction of cell apoptosis. GL63 may have translational potential as an effective drug or preventive agent for hepatocarcinoma. The doses of GL63 that effectively demonstrate chemopreventive effects without toxicity for humans must be examined in future clinical studies.

\section{Acknowledgements}

The present study was supported by research grants from the Health and Family Planning Commission of Hebei Province (Shijiazhuang, China; grant no. 20150634) and the Tumor Research Institute, The Fourth Affiliated Hospital, Hebei Medical University (Shijiazhuang, China). The authors appreciate the generous support from Dr Yueping Liu, Dr Xiaoling Wang and Dr Huichai Yang for the pathological images.

\section{References}

1. Hussain SA, Ferry DR, El-Gazzaz G, Mirza DF, James ND, McMaster P and Kerr DJ: Hepatocellular carcinoma. Ann Oncol 12: 161-172, 2001.

2. Yang TS, Wang CH, Hsieh RK, Chen JS and Fung MC: Gemcitabine and doxorubicin for the treatment of patients with advanced hepatocellular carcinoma: A phase I-II trial. Ann Oncol 13: 1771-1778, 2002.

3. Okuda H: Hepatocellular carcinoma development in cirrhosis. Best Pract Res Clin Gastroenterol 21: 161-173, 2007.

4. Ikeda K: Current therapy for hepatocellular carcinoma. Nihon Rinsho 68: 1129-1136, 2010 (In Japanese).

5. Zhao JA, Peng L, Geng CZ, Liu YP, Wang X, Yang HC and Wang SJ: Preventive effect of hydrazinocurcumin on carcinogenesis of diethylnitrosamine-induced hepatocarcinoma in male SD Rats. Asian Pac J Cancer Prev 15: 2115-2121, 2014.

6. Anand P, Sundaram C, Jhurani S, Kunnumakkara AB and Aggarwal BB: Curcumin and cancer: An 'old-age' disease with an 'age-old' solution. Cancer Lett 267: 133-164, 2008.

7. Dai XZ, Yin HT, Sun LF, Hu X, Zhou C, Zhou Y, Zhang W, Huang XE and Li XC: Potential therapeutic efficacy of curcumin in liver cancer. Asian Pac J Cancer Prev 14: 3855 3859,2013

8. Anand P, Kunnumakkara AB, Newman RA and Aggarwal BB: Bioavailability of curcumin: Problems and promises. Mol Pharm 4: 807-818, 2007.

9. Appiah-Opong R, de Esch I, Commandeur JN, Andarini M and Vermeulen NP: Structure-activity relationships for the inhibition of recombinant human cytochromes $\mathrm{P} 450$ by curcumin analogues. Eur J Med Chem 43: 1621-1631, 2008.

10. Sharma RA, Steward WP and Gescher AJ: Pharmacokinetics and pharmacodynamics of curcumin. Adv Exp Med Biol 595: 453-470, 2007.

11. Padhye S, Chavan D, Pandey S, Deshpande J, Swamy KV and Sarkar FH: Perspectives on chemopreventive and therapeutic potential of curcumin analogs in medicinal chemistry. Mini Rev Med Chem 10: 372-387, 2010.

12. Agrawal DK and Mishra PK: Curcumin and its analogues: Potential anticancer agents. Med Res Rev 30: 818-860, 2010.

13. Liang G, Yang SL, Shao LL, Zhao CG, Xiao J, Lv YX, Yang J, Zhao Y and Li XK: Synthesis, structure, and bioevaluation of 2,5-bis(arylmethenyl)cyclopentanones. J Asian Nat Prod Res 10: 957-965, 2008.

14. Liang G, Yang S, Zhou H, Shao L, Huang K, Xiao J, Huang Z and Li X: Synthesis, crystal structure and anti-inflammatory properties of curcumin analogues. Eur J Med Chem 44 915-919, 2009.

15. Liang G, Yang S, Jiang L, Zhao Y, Shao L, Xiao J, Ye F, Li Y and $\mathrm{Li} \mathrm{X}$ : Synthesis and anti-bacterial properties of mono-carbonyl analogues of curcumin. Chem Pharm Bull (Tokyo) 56: 162-167, 2008.

16. Robinson TP, Ehlers T, Hubbard IV RB, Bai X, Arbiser JL, Goldsmith DJ and Bowen JP: Design, synthesis, and biological evaluation of angiogenesis inhibitors: Aromatic enone and dienone analogues of curcumin. Bioorg Med Chem Lett 13: $115-117,2003$
17. Ohtsu H, Xiao Z, Ishida J, Nagai M, Wang HK, Itokawa H, Su CY, Shih C, Chiang T, Chang E, et al: Antitumor agents. 217. Curcumin analogues as novel androgen receptor antagonists with potential as anti-prostate cancer agents. J Med Chem 45: 5037-5042, 2002.

18. Weng Q, Fu L, Chen G, Hui J, Song J, Feng J, Shi D, Cai Y, Ji J and Liang G: Design, synthesis, and anticancer evaluation of longchain alkoxylated mono-carbonyl analogues of curcumin. Eur $\mathbf{J}$ Med Chem 103: 44-55, 2015.

19. Xiao J, Tan Y, Pan Y, Liang G, Qu C, Zhang X, Zhang Y, $\mathrm{Li} X$ and Yang $\mathrm{H}$ : A new cyclooxygenase-2 inhibitor, (1E,4E)-1,5-bis(2-bromophenyl)penta-1,4-dien-3-one (GL63) suppresses cyclooxygenase-2 gene expression in human lung epithelial cancer cells: Coupled mRNA stabilization and posttranscriptional inhibition. Biol Pharm Bull 33: 1170-1175, 2010.

20. Liang G, Shao L, Wang Y, Zhao C, Chu Y, Xiao J, Zhao Y, Li X and Yang S: Exploration and synthesis of curcumin analogues with improved structural stability both in vitro and in vivo as cytotoxic agents. Bioorg Med Chem 17: 2623-2631, 2009.

21. Xiao J, Chu Y, Hu K, Wan J, Huang Y, Jiang C, Liang G and Li X: Synthesis and biological analysis of a new curcumin analogue for enhanced anti-tumor activity in HepG 2 cells. Oncol Rep 23: 1435-1441, 2010.

22. Pan Y, Xiao J, Liang G, Wang M, Wang D, Wang S and Yang H: A new curcumin analogue exhibits enhanced antitumor activity in nasopharyngeal carcinoma. Oncol Rep 30: 239-245, 2013.

23. Reiser D (ed): Animal Ethics. In: Encylopedia of Corporate Social Responsibility. Springer, Berlin Heidelberg, pp106-110, 2013.

24. Theise ND, Curado MP and Franceschi S: Hepatocellular carcinoma. In: WHO Classification of Tumors of the Digestive System. Bosman FT, Carneiro F, Hruban RH and Theise ND (eds). 4th edition. IARC Press, Lyon, pp205-216, 2010.

25. Porter AG and Jänicke RU: Emerging roles of caspase-3 in apoptosis. Cell Death Differ 6: 99-104, 1999.

26. Taras D, Blanc JF, Rullier A, Dugot-Senant N, Laurendeau I, Vidaud $\mathrm{M}$ and Rosenbaum J: Pravastatin reduces lung metastasis of rat hepatocellular carcinoma via a coordinated decrease of MMP expression and activity. J Hepatol 46: 69-76, 2007.

27. Franco-Bourland RE and Méndez-Sánchez N: The liver is the key organ for the development of metabolic syndrome. Ann Hepatol 10: 216-217, 2011.

28. Peraino C: Initiation and promotion of liver tumorigenesis. Natl Cancer Inst Monogr 58: 55-61, 1981.

29. Sivalokanathan S, Ilayaraja $\mathbf{M}$ and Balasubramanian MP: Antioxidant activity of Terminalia arjuna bark extract on $\mathrm{N}$-nitrosodiethylamine induced hepatocellular carcinoma in rats. Mol Cell Biochem 281: 87-93, 2006.

30. Pereira MA, Herren-Freund SL, Britt AL and Khoury MM: Effect of coadministration of phenobarbital sodium on N-nitrosodiethylamine-induced gamma-glutamyltransferase-positive foci and hepatocellular carcinoma in rats. J Natl Cancer Inst 72: 741-744, 1984.

31. Fen F, Pascale RM, Simile MM, De Miglio MR, Muroni MR and Calvisi D: Genetic alterations in liver carcinogenesis: Implications for new preventive and therapeutic strategies. Crit Rev Oncog 11: 19-62, 2000.

32. Al-Rejaie SS, Aleisa AM, Al-Yahya AA, Bakheet SA, Alsheikh A, Fatani AG, Al-Shabanah OA and Sayed-Ahmed MM: Progression of diethylnitrosamine-induced hepatic carcinogenesis in carnitine-depleted rats. World J Gastroenterol 15: 1373-1380, 2009.

33. Verna L, Whysner J and Williams GM: N-nitrosodiethylamine mechanistic data and risk assessment: Bioactivation, DNA-adduct formation, mutagenicity, and tumor initiation. Pharmacol Ther 71: 57-81, 1996.

34. Granado-Serrano AB, Martín MA, Bravo L, Goya L and Ramos S: A diet rich in cocoa attenuates $\mathrm{N}$-nitrosodiethylamine-induced liver injury in rats. Food Chem Toxicol 47: 2499-2506, 2009.

35. Sreepriya M and Bali G: Chemopreventive effects of embelin and curcumin against N-nitrosodiethylamine/phenobarbital-induced hepatocarcinogenesis in Wistar rats. Fitoterapia 76: 549-555, 2005.

36. Sivaramakrishnan V, Shilpa PN, Praveen Kumar VR and Niranjali Devaraj S: Attenuation of N-nitrosodiethylamine-induced hepatocellular carcinoma by a novel flavonol-Morin. Chem Biol Interact 171: 79-88, 2008.

37. Kelloff GJ, Lieberman R, Steele VE, Boone CW, Lubet RA, Kopelovitch L, Malone WA, Crowell JA and Sigman CC: Chemoprevention of prostate cancer: Concepts and strategies. Eur Urol 35: 342-350, 1999.

38. Schindler CW: Series introduction. JAK-STAT signaling in human disease. J Clin Invest 109: 1133-1137, 2002. 
39. Mitchell TJ and John S: Signal transducer and activator of transcription (STAT) signalling and T-cell lymphomas. Immunology 114: 301-312, 2005.

40. Liu Y, Wang L, Wu Y, Lv C, Li X, Cao X, Yang M, Feng D and Luo Z: Pterostilbene exerts antitumor activity against human osteosarcoma cells by inhibiting the JAK2/STAT3 signaling pathway. Toxicology 304: 120-131, 2013.

41. Wung BS, Hsu MC, Wu CC and Hsieh CW: Resveratrol suppresses IL-6-induced ICAM-1 gene expression in endothelial cells: Effects on the inhibition of STAT3 phosphorylation. Life Sci 78: 389-397, 2005.

42. Du W, Hong J, Wang YC, Zhang YJ, Wang P, Su WY, Lin YW, Lu R, Zou WP, Xiong H and Fang JY: Inhibition of JAK2/STAT3 signalling induces colorectal cancer cell apoptosis via mitochondrial pathway. J Cell Mol Med 16: 1878-1888, 2012.

43. Gross A, McDonnell JM and Korsmeyer SJ: BCL-2 family members and the mitochondria in apoptosis. Genes Dev 13: 1899-1911, 1999.

44. Granado-Serrano AB, Martín MA, Bravo L, Goya L and Ramos S: Quercetin induces apoptosis via caspase activation, regulation of $\mathrm{Bcl}-2$, and inhibition of PI-3-kinase/Akt and ERK pathways in a human hepatoma cell line (HepG2). J Nutr 136: 2715-2721, 2006.
45. Estaquier J, Vallette E, Vayssiere JL and Mignotte B: The mitochondrial pathways of apoptosis. Adv Exp Med Biol 942: 157-183, 2012

46. Martin KR: Targeting apoptosis with dietary bioactive agents. Exp Biol Med (Maywood) 231: 117-129, 2006.

47. Würstle ML, Laussmann MA and Rehm M: The central role of initiator caspase-9 in apoptosis signal transduction and the regulation of its activation and activity on the apoptosome. Exp Cell Res 318: 1213-1220, 2012.

48. Fuke H, Shiraki K, Sugimoto K, Tanaka J, Beppu T, Yoneda K, Yamamoto N, Ito K, Masuya M and Takei Y: Jak inhibitor induces $S$ phase cell-cycle arrest and augments TRAILinduced apoptosis in human hepatocellular carcinoma cells. Biochem Biophys Res Commun 363: 738-744, 2007.

49. Park DH, Shin JW, Park SK, Seo JN, Li L, Jang JJ and Lee MJ: Diethylnitrosamine (DEN) induces irreversible hepatocellular carcinogenesis through overexpression of G1/S-phase regulatory proteins in rat. Toxicol Lett 191: 321-326, 2009. 